\title{
Increased risk of tuberculosis transmission in families with microepidemics
}

\author{
R. Vidal*, M. Miravitlles*, J.A. Caylà**, M. Torrella*, J. de Gracia*, F. Morell*
}

Increased risk of tuberculosis transmission in families with microepidemics. R. Vidal, M. Miravitlles, J.A. Caylà, M. Torrella, J. de Gracia, F. Morell. @ERS Journals Ltd 1997.

ABSTRACT: In the present study, we analysed: 1) prevalence of TB infection and incidence of disease among family contacts of a cohort of patients with TB; 2 ) differential characteristics of families with microepidemics and families with $\leq 1$ new case of TB; and 3 ) efficacy of chemoprophylaxis in this group of contacts.

Three thousand and seventy one family contacts of 635 patients with TB were studied. The study consisted of tuberculin skin testing and chest radiography in all cases, and bacteriological studies when active disease was suspected. Contacts were classified as belonging to: families with microepidemics (FME) (those with $\geq 2$ new cases of TB); families with one new case; and families with with no new cases. Chemoprophylaxis was prescribed in contacts following standard recommendations; all were followed up for 12-18 months. Rates of TB infection and disease among families, as well as the incidence of $\mathrm{TB}$ disease between those compliant and noncompliant with chemoprophylaxis were compared.

Among the 3,071 contacts, 1,264 (41\%) were infected and $176(6 \%)$ had TB. Twenty two families with FME (3\%) yielded 55 new cases of TB. The prevalence of infection (excluding the TB cases) was $80 \%$ in families with FME, $52 \%$ in families with one new case, and $41 \%$ in families with no new case (odds ratio (OR) $3.7 ; 95 \%$ confidence interval $(95 \% \mathrm{CI}) \mathbf{2 . 1 - 6 . 5})$. Sputum smears were positive in $53 \%$ of cases in FME and $24 \%$ in non-FME families (OR 3.4; 95\% CI 1.7-6.5). Bronchial sample cultures were positive in $84 \%$ of patients from FME families but in only $40 \%$ of those from non-FME families (OR 7.5; 95\% CI 3.6-15.8).

Chemoprophylaxis was prescribed in 356 contacts, of whom 296 complied and generated only one new case of TB, whilst there were 13 new cases among the 60 who did not comply (OR 81.6; 95\% CI 26.7-248.7).

This study showed the prevalence of infection and incidence of tuberculosis among family contacts of patients with newly diagnosed tuberculosis to be very high. A small number of families with microepidemics accounted for most new cases of tuberculosis, which were also more infectious. The extremely high risk of transmission in these families, together with the proven efficacy of chemoprophylaxis, justifies prescription of chemoprophylaxis to all their members, regardless of age. Eur Respir J 1997; 10: 1327-1331.
*Servei de Pneumologia, Hospital General Universitari Vall d'Hebron, Barcelona, Spain. **Servei d'Epidemiologia, Institute Municipal da la Salut, Barcelona, Spain.

Correspondence: R. Vidal

Servei de Pneumologia

HGU Vall d'Hebron

P. Vall d'Hebron 119-129

08035 Barcelona

Spain

Keywords: Chemoprophylaxis

contact tracing

epidemology

microepidemics

tuberculosis

tuberculosis transmission

Received: August 121996

Accepted after revision February 21997

This work has been supported in part by a Grant from Fondo de Investigaciones Sanatarias de la Seguridad Social (FISS No. 88/2026), and by a grant from the Sociedad Española de Neumología y Cirugía Torácica (SEPAR/Merrell Dow 1988).
Tuberculosis (TB) is almost exclusively transmitted by air from patients with pulmonary involvement. The risk of infection depends on factors related to the patient, the environment and the individuals exposed [1].

Delay in the diagnosis and treatment of patients clearly increases the risk of disease transmission [2]. This risk is greater in acid-fast smear-positive patients and is proportional to the bacillar density of their respiratory samples [2].

Proximity and persistence of contact are the main environmental factors. The greatest risk of infection is presented by people living together, and is lower in distant relatives, school or occupational contacts [3]. The volume of air shared by the household of the patient also influences transmission; small dwellings with deficient ventilation and overcrowding present a greater danger of transmission. The most susceptible contacts are the very young and those with immunodeficiency [4].

The objective of a TB control programme is to eliminate $\mathrm{TB}$ by breaking the chain of transmission $[5,6]$. This can be achieved through the rapid identification and effective treatment of infectious cases [6]. In industrial countries, such as Spain, with a case notification rate of 40 new cases per 100,000 population in 1992 [7] and a high level of healthcare, systematic study of contacts living together is a useful measure of TB control [3]. Study of close contacts permits detection of recent infections, chemoprophylaxis (CP), and early diagnosis of new cases of TB.

The present study was conducted to investigate: 1) prevalence of TB infection and incidence of disease among family contacts of patients with TB;2) differential 
characteristics of families with microepidemics and families with $\leq 1$ new case of TB; and 3 ) efficacy of $\mathrm{CP}$ in this group of contacts.

\section{Methods}

\section{Study population}

This study was performed in a general hospital in Barcelona, covering a population of 700,000. From 1989 to 1994 , the family contacts of all new patients with TB were studied prospectively. The inclusion criteria for the TB patients were that: 1) they were human immunodeficiency virus (HIV)-seronegative; and 2) their families agreed to be studied at our centre. Traditional families and persons who had lived continuously with the patient (communes, hetero- or homosexual couples, etc.) were considered as contacts.

\section{Diagnosis of TB infection and disease}

The study protocol included: physical examination; tuberculin skin test (TST) by the Mantoux method (0.1 $\mathrm{mL}$ of purified protein derivative (PPD) RT-23 at a concentration of 5 tuberculin units (TU)); and chest radiography, irrespective of TST results. Contacts of index cases with positive sputum smears and cultures for Mycobacterium tuberculosis, and those under the age of 25 yrs with a negative initial TST were given a further test after 2-3 months. Radiography was only repeated in contacts with TST conversion.

When chest radiography showed abnormalities consistent with TB, bacteriological studies of three spontaneous sputum samples (sputum smears for acid-fast bacilli and culture in Löwenstein-Jensen medium) were conducted. Other relevant samples were analysed in particular cases, including: pleural fluid; urine; bronchoscopic specimens or biopsies of diverse organs.

Contacts were considered TB-infected if: 1) initial TST was $\geq 6 \mathrm{~mm}$ in those not vaccinated; 2 ) initial TST was $\geq 10 \mathrm{~mm}$ in the vaccinated; or 3 ) initial TST had been negative and a difference $\geq 12 \mathrm{~mm}$ was observed in the second reaction (TST conversion) [8].

HIV serology was determined, with informed consent, in all contacts in whom HIV infection was suspected. Families with any HIV-seropositive contact were excluded from the analysis, owing to the different susceptibility of HIV-infected individuals to tuberculous infection and disease [9].

\section{Classification of families}

The families studied were divided into three groups, according to the number of TB cases detected: 1) families with familial microepidemics (FME), i.e. those in which $\geq 2$ new cases of TB were diagnosed in the initial study (Group A); 2) families with a single case, apart from the index case (Group B); and 3) families in which no new case was detected (Group C).

This classification is based on the fact that when two or more new TB cases appear among contacts, this is clearly greater than the expected number of new cases. Thus, the presence of factors that increase the risk of transmission must be suspected [10].

\section{Chemoprophylaxis}

Chemoprophylaxis with isoniazid was prescribed to those contacts in whom it was indicated following local recommendations [8]. Briefly, primary $\mathrm{CP}$ was prescribed to those younger than 25 yrs with negative TST close contacts of smear-positive index cases. Secondary $\mathrm{CP}$ was prescribed to TST-positive close contacts of smear-positive index cases and those who suffered a TST conversion. The dosage used was $300 \mathrm{mg} \cdot \mathrm{day}^{-1}$ for those aged $\geq 15 \mathrm{yrs}$ and $10 \mathrm{mg} \cdot \mathrm{kg}^{-1}$ q.d. for children aged $<15$ yrs. Primary CP was prescribed for 2.5 months and secondary for 9 months.

Contacts underwent long-term follow-up (12-18 months) to detect the possible onset of TB. Those who were prescribed CP were followed up at 1, 2, 4, 6 and 9 months, and at 12-18 months after the completion of CP. Those who took less than $80 \%$ of the medication prescribed were considered to be noncompliant.

\section{Statistical analysis}

Stratification was made according to the number of new TB cases detected in the families, following the criteria expressed in classification of families.

Comparisons between groups were made by contingency tables. The Chi-squared test was used for statistical analysis. The odds ratio (OR) with $95 \%$ confidence intervals (95\% CIs) was applied as a means of statistical association.

\section{Results}

\section{Index cases}

Of 1,200 patients with a diagnosis of TB during the study period, 635 fulfilled inclusion criteria. The mean age of index cases was 36 yrs (SD 19 yrs), 416 (66\%) were males, and 497 (78\%) had pulmonary TB. The disease was exclusively extrapulmonary or pleural in 138 cases $(22 \%)$.

\section{Tuberculosis infection and disease among contacts}

A total of 3,071 contacts from 635 families was studied and $176(6 \%)$ new cases of TB detected at the initial examination (fig. 1). Of these, $13(7 \%)$ were considered to be initiators of the familial transmission, since they showed more severe involvement on chest radiography than the case initially diagnosed, i.e. cavitary vs noncavitary lesions.

Of the 2,895 contacts without TB, 1,264 (44\%) were infected.

\section{Differential characteristics of families with microepi- demics}

A familial microepidemic, presenting $\geq 2$ new cases of TB, was detected in $22(3 \%)$ of the families studied: two new cases were diagnosed in 12 families, three in nine families, and four in one family. A total of 135 (4\%) of the 3,071 contacts studied belonged to families with FME. Recent immigration from countries with a 
Table 1. - Characteristics of families with and without microepidemics

\begin{tabular}{|c|c|c|c|c|c|}
\hline Characteristic & Total & Group A & Group B & Group C & Group B+C \\
\hline Families & $635(100)$ & $22(3)$ & $121(19)$ & $492(77)$ & $613(96)$ \\
\hline Contacts & $3,071(100)$ & $135(4)$ & $585(19)$ & $2,351(76)$ & $2,963(95)$ \\
\hline TST-positive* & $1,264 / 2,895(44)$ & $64 / 80(80)$ & $240 / 464(52)$ & $960 / 2,351(41)$ & $1,200 / 2,815(43)$ \\
\hline OR $(95 \% \mathrm{CI})$ & & \multicolumn{2}{|c|}{$\mathrm{A}$ vs $\mathrm{B}=3.7$} & \multicolumn{2}{|c|}{ A vs $\mathrm{B}+\mathrm{C}=5.7$} \\
\hline $\begin{array}{l}\text { New TB } \\
\text { OR }(95 \% \text { CI) }\end{array}$ & $176 / 3,071(5.7)$ & $\begin{array}{r}55 / 135(41) \\
\mathrm{A} v s \mathrm{~B}\end{array}$ & $\begin{array}{l}121 / 585(21) \\
8-3.9)\end{array}$ & $\mathrm{A} v s \mathrm{~B}+\mathrm{C}=16.0$ & $\begin{array}{l}121 / 2,938(4) \\
(11.8-21.7)\end{array}$ \\
\hline $\begin{array}{c}\text { Sputum smear positive } \\
\text { OR }(95 \% \text { CI })\end{array}$ & $58 / 176(33)$ & $\begin{array}{r}29 / 55(53) \\
\mathrm{A} v s \mathrm{~B}\end{array}$ & $\begin{array}{l}29 / 121(24) \\
7-6.5)\end{array}$ & 0 & $29 / 121(24)$ \\
\hline $\begin{array}{l}\text { Culture positive } \\
\text { OR }(95 \% \mathrm{CI})\end{array}$ & \multicolumn{4}{|c|}{$\mathrm{A}$ vs $\mathrm{B}=7.5$} & 49/121 (40) \\
\hline $\begin{array}{l}\text { Family history of poor } \\
\text { compliance with TB } \\
\text { treatment } \\
\qquad \text { OR }(95 \% \mathrm{CI})\end{array}$ & 64/653 (10) & $\begin{array}{r}10 / 22(45) \\
\mathrm{A} \text { vs } \mathrm{B}\end{array}$ & $\begin{array}{l}35 / 121(29) \\
8-5.1)\end{array}$ & $\begin{array}{l}19 / 492(4) \\
\quad \mathrm{A} \text { vs } \mathrm{B}+\mathrm{C}=\end{array}$ & $\begin{array}{l}54 / 613(9) \\
(4.1-19.3)\end{array}$ \\
\hline
\end{tabular}

Values are presented as absolute number and percentage in parenthesis. Group A: families with two or more new cases of TB in addition to the index case; Group B: families with a single new case; Group C: families with no new case; Group B+C: families without microepidemics. *: for those contacts without TB. TST: tuberculin skin test; TB: tuberculosis; OR: odds ratio; 95\% CI: $95 \%$ confidence interval.

high prevalence of TB was reported in two families, drug addiction in two, and there was one commune. Only one new case of TB was diagnosed in 121 families $(19 \%)$, and no new cases in $492(78 \%)$.

TB was newly diagnosed by the study in 55 of 135 contacts in families with FME (41\%). In contrast, in families with a single new case, TB was newly diagnosed in 121 out of 585 contacts $(21 \%)$ (table 1). Of the new TB cases detected by the study of contacts, $31 \%$ belonged to a family with FME (55 out of 176).

Sputum smears for acid-fast bacilli were positive in $53 \%$ of patients from FME families and in $24 \%$ of those from non-FME families. Similarly, culture of bronchial samples was positive in $83 \%$ of patients from FME families and $40 \%$ of those from non-FME families (table 1).

The existence of other relatives with diagnosis of TB at least 1 year prior to diagnosis of the index case, and who had not complied with treatment, was assessed. This antecedent was significantly more frequent in FME families (table 1). TB was rediagnosed in 15 out of 129 of these contacts (12\%), and four of these were considered to be initiators of the familial transmission.

The prevalence of infection, once the TB cases had been excluded, was significantly higher in families with FME than in non-FME families (table 1).

\section{Chemoprophylaxis and follow-up}

Among TB-free contacts, $79 \%$ were followed-up over 12-18 months $(2,284$ out of 2,895). New cases of TB were diagnosed during this period in 20 of the 2,284 $(0.9 \%)$.

All TST-positive contacts from families with FME were prescribed secondary $\mathrm{CP}$ with isoniazid, regardless

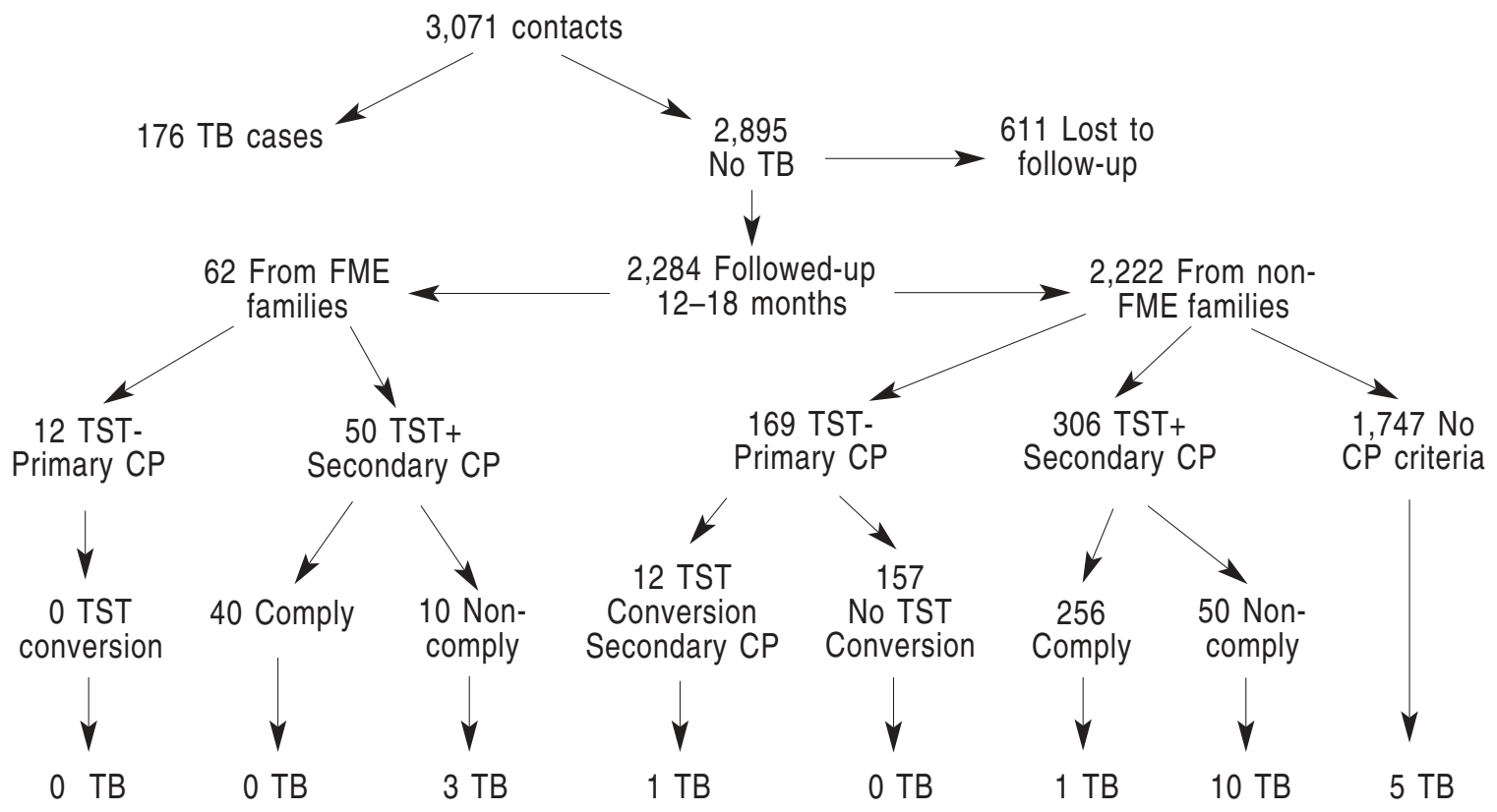

Fig. 1. - Follow-up of 3,071 contacts of patients with TB. TB: tuberculosis; FME: familial microepidemic; TST: tuberculin skin test; CP: chemoprophylaxis; TST-: negative TST; TST+: positive TST. 
of age. Primary CP was also prescribed to all TST-negative contacts.

Contacts who complied with secondary $\mathrm{CP}$ presented only two cases of TB, 6 months after completion ( 2 out of 320); whereas, TB was diagnosed during follow-up in 13 of the $60(22 \%)$ who did not comply (OR 81.6; CI 95\% 26.7-248.7).

In non-FME families, 50 contacts did not comply with CP, 10 of whom presented TB (20\%), compared with 3 out of $10(30 \%)$ in FME families (OR 1.7; CI 95\% 0.4-7.8) (fig. 1).

Of the 2,222 contacts from non-FME families, 1,747 did not fulfil the criteria for CP; and TB was diagnosed in only 5 of the $1,747(0.3 \%)$.

\section{Discussion}

In the present study, we demonstrated the following: 1) there is a high prevalence of TB infection and a high incidence of disease among family contacts of patients with newly diagnosed TB;2) a small number of families accounts for most newly detected cases of TB, which are also more infectious; and 3) chemoprophylaxis is very effective in family contacts, and should be particularly recommended to all contacts in families with microepidemics, regardless of age.

An overall incidence of $6 \%$ new TB cases and a prevalence of infection of $43 \%$ was observed among contacts. The diagnosis of new TB cases in families with FME was more frequent than in families with a single new case (41 versus 21\%), and was approximately 10 times higher than in the group of families without FME (4\%) and in all of the contacts studied $(6 \%)$. It was observed that $3 \%$ of families with FME generated up to a third of new TB cases detected in the contact study. On average, each index case produced 2.5 TB cases in FME families compared with 0.19 TB cases in families without FME. The prevalence of infection $(80 \%)$ was also significantly higher than in families with a single new case $(51 \%)$, and double that of the remaining families classified as FME.

Microepidemic outbreaks may pass unnoticed when the prevalence of TB is high. Thus, as the incidence of TB decreases, and noninfected subjects take predominance in the community, new cases are detected mainly as microepidemics concentrated around a small number of index cases [11, 12]. Microepidemic outbreaks occur mainly in prisons $[13,14]$ and residences for the homeless [15]; however, they have also been observed in schools [16-18], colleges [12], religious communities [19], and in the family environment [20, 21]. Significant microepidemics have recently been reported in communities with a high proportion of HIV-positive individuals [22], due, in particular, to intravenous drug use [9]; furthermore, their high susceptibility to the disease has favoured the propagation of resistant strains in microepidemics [23]. Because of this increased susceptibility, HIV-infected subjects were excluded from the study.

Microepidemics of TB outside the home raise social awareness and result in instigation of special preventive measures $[8,9,11-13]$. Conversely, extreme preventive measures are not usually applied to the excessive aggregation of cases within a family, perhaps because of lack of data on intrafamily transmission. This attitude contrasts with the present finding that $53 \%$ of new cases detected in FME families were highly infectious, with positive sputum smears. Therefore, "respiratory" isolation must have special importance, particularly when rapid conversion to a negative condition does not occur, and exposure of an infant or an immunosuppressed individual to the patient may continue. It must be remembered that this often applies to families with restricted living conditions or social risk factors that render isolation of the patient difficult. In such cases, the possibility of hospitalization to ensure isolation should be considered.

This study has some limitations: 1) HIV serology was determined only in patients with known risk factors, and those who were positive were excluded from the study. It is possible that some HIV-positive patients were not diagnosed; nevertheless, all patients responded successfully to the standard treatment, thus rendering the possibility of transmission of resistant strains highly improbable; 2) conventional contact tracing was used to identify transmission, as the technique of restriction fragment length polymorphism (RFLP) analysis was not available at the time of the study. This latter technique has proved to be superior in population-based studies [24, 25]; however, our results show a high yield using the traditional methods in enclosed environments, such as the family setting; 3 ) $21 \%$ of contacts were lost to follow-up. We do not believe this influences the results as the majority were adults (with lower risk of infection and disease) and some members of their families came to control centres and were questioned about relatives who refused to attend. In this way, no further case of TB could be detected among those who were lost to follow-up.

There was a high frequency of a history of relatives with incorrectly-treated $\mathrm{TB}$, at least $1 \mathrm{yr}$ prior to diagnosis of the index case, in the families with at least one case other than the initial one (45\% for FME families, compared with $28 \%$ for those with only one new case). This implies that the long-term presence of an individual with active disease within the family facilitates the occurrence of a FME. In a great many cases, this individual would be the initial case in the family. Moreover, the greater proportion of acid-fast smearpositive patients $(80 \%)$ among new cases in families with FME suggests a longer evolution time from contagion as a consequence of delay in the diagnosis of the index case.

Although study of a possible infection is well-accepted and even requested by relatives, $\mathrm{CP}$ is seldom recommended and is subject to a high abandonment rate [26]. In our study, we considered the risk of TB developing in FME families to be so high that it justified the application of primary or secondary $\mathrm{CP}$, regardless of age. Noncompliance of $\mathrm{CP}$ resulted in a very high incidence of late TB $(30 \%)$. In our opinion, this justifies strict vigilance of compliance, administration of directly observed preventive therapy, and $\mathrm{CP}$ regardless of age [27].

In summary, family contacts of patients with newly diagnosed tuberculosis show a high prevalence of tuberculous infection and a high incidence of the disease. A small number of families generate most new tuberculous 
patients diagnosed in the study of contacts, and these cases are particularly contagious. Identification of a familial microepidemic is important since it necessitates extension of contact tracing, and the indication of chemoprophylaxis must be extended to all family contacts without active disease. Furthermore, a history of a relative with previously diagnosed tuberculosis should alert the physician to the possibility of a familial microepidemic. These data emphasize the importance of careful attention to detailed study of contacts, and to treatment and chemoprophylaxis in this special risk group.

Acknowledgements: The authors are indebted to T.R. Frieden from the Tuberculosis Program of New York City for his helpful suggestions on the manuscript, and to C. O'Hara for help with translation.

\section{References}

1. Rieder HL. Epidemiology of tuberculosis in Europe. Eur Respir J 1995; 8 (Suppl. 20): 620s-632s.

2. Glassroth J. The physician's role in tuberculosis prevention. Clin Chest Med 1989; 10: 365-374.

3. Center for Disease Control. A strategic plan for the elimination of tuberculosis. MMWR Morb Mortal Wkly Rep 1989; 38 (Suppl. 3): 1-25.

4. Recommendations of the Advisory Committee for Elimination of Tuberculosis. Screening for tuberculosis and tuberculosis infection in high-risk populations. $M M W R$ Morb Mortal Wkly Rep 1990; 39 (Suppl. RR-8): 1-7.

5. Clancy L, Rieder HL, Enarson DA, Spinaci S. Tuberculosis elimination in the countries of Europe and other industrialized countries. Eur Respir J 1991; 4: 1288-1295.

6. Enarson DA. The International Union Against Tuberculosis and Lung Diseases Model National Tuberculosis Programmes. Tuber Lung Dis 1995; 76: 95-99.

7. Collaborative Group for the Study of Tuberculosis in Spain. Epidemiological trends of tuberculosis in Spain from 1988 to 1992. Tuber Lung Dis 1995; 76: 522-528.

8. Grupo de Trabajo sobre Tuberculosis. Consenso nacional para el control de la tuberculosis en España. Med Clin (Barc) 1992; 98: 24-31.

9. Caylà JA, García de Olalla $\mathrm{P}$, Galdós-Tangüis $\mathrm{H}$, et al. The influence of intravenous drug use and HIV infection in the transmission of tuberculosis. AIDS 1996; 10: 95-100.

10. Farga V. Epidemiología de la tuberculosis. In: Farga V, ed. Santiago de Chile, Mediterràneo Ed., 1992.

11. Veen J. Microepidemics of tuberculosis: the stone-inthe-pond principle. Tuber Lung Dis 1992; 73: 73-76.

12. Braden CR and an Investigative Team. Infectiousness of a university student with laryngeal and cavitary tuberculosis. Clin Infect Dis 1995; 21: 565-570.

13. Chaves F, Dronda F, González A, Fernández F, Catalán S. Tuberculosis en población penitenciaria: estudio de 138 casos. Med Clin (Barc) 1993; 101: 525-529.

14. Martín V, González P, Caylà JA, et al. Case-finding of pulmonary tuberculosis on admission to a penitentiary centre. Tuber Lung Dis 1994; 74: 49-53.

15. Nolan CM, Elarth AM, Barr H, Saeed AM, Risser DR. An outbreak of tuberculosis for homeless men. A description of its evolution and control. Am Rev Respir Dis 1991; 143: 257-261.

16. De March P, Boqué MA. Brotes explosivos de tuberculosis: a propósito de diez epidemias escolares en Barcelona y provincia. Rev Clin Esp 1988; 183: 24-29.

17. Wales JM, Buchan AR, Cookson JA, Jones DA, Marshall BSM. Tuberculosis in a primary school: the Uppingham outbreak. Br Med J 1985; 291: 1039-1040.

18. Shannon A, Kelly P, Lucey M, Cooney M, Corcoran P, Clancy L. Isoniazid-resistant tuberculosis in a school outbreak: the protective effect of BCG. Eur Respir J 1991; 4: 778-782.

19. Dutt AK, Mehta JB, Whitaker BJ, Westmoreland H. Outbreak of tuberculosis in a church. Chest 1995; 107 : 447-452.

20. Vidal R, Roca R, Miravitlles M, De Gracia J, Nubiola AR. Microepidemia familiar de tuberculosis. Med Clin (Barc) 1990; 95: 221-223.

21. Cabañes M, Sánchez S, Franco J. Brote familiar de tuberculosis respiratoria. An Med Interna 1991; 8: 291-293.

22. Center for Disease Control. Tuberculosis outbreak among persons in a residential facility for HIV-infected persons: San Francisco. MMWR Morb Mortal Wkly Rep 1991; 40 (Suppl. 8): 129-131.

23. McGowan Jr JE. Nosocomial tuberculosis: new progress in control and prevention. Clin Infect Dis 1995; 21: 489-505.

24. Alland D, Kalkut GE, Moss AR, et al. Transmission of tuberculosis in New York city: an analysis by DNA fingerprinting and conventional epidemiologic methods. N Engl J Med 1994; 330: 1710-1716.

25. Small PM, Hopewell PC, Singh SP, et al. The epidemiology of tuberculosis in San Francisco: a populationbased study using conventional and molecular methods. N Engl J Med 1994; 330: 1703-1709.

26. Sorresso DJ, Mehta JB, Harvill LM, Bentley S. Underutilization of isoniazid chemoprophylaxis in tuberculosis contacts 50 years of age and older: a prospective analysis. Chest 1995; 108: 706-711.

27. World Health Organization. WHO Report on the Tuberculosis Epidemic, 1995, Geneva, 1995; WHO/ TB/95.183. 